\title{
MANAGEMENT OF INTRACRANIAL ARACHNOID AND PORENCEPHALICCYSTS (CONSERVATIVE VERSUS SURGICAL)
}

By

\author{
Ali M. El-Sherbiny, Islam M. Al-Aghory and Osama M. El-Ghannam \\ Neurosurgery Department, Faculty of Medicine, Al-Azhar University, Cairo, Egypt \\ Corresponding author: Ali M Elsherbiny, E-mail: dr_ali_magdi@yahoo.com
}

\begin{abstract}
Background: Arachnoid cysts (ACs) are benign developmental cysts that occur along the craniospinal axis. Arachnoid cysts comprise $1 \%$ of all intracranial space-occupying lesions.

Objective: To evaluate the cases of intracranial arachnoid cysts clinically and radiologically and the possibility of surgery.

Patients and Methods: The study was done prospectively on 22 patients presented with intracranial arachnoidcysts (15 of them were medically managed, and 7 of them were surgically managed) in the Neurosurgery Department, Al-Azhar and Alexandria Universities on patients suffering from extra-axial intracranial arachnoid cysts. The study was performed through the period from March 2019 to February 2020, and the follow up period was 6 months. All cases, either surgical or conservative cases, had been evaluated regarding (clinical improvement of symptoms, radiological reduction in size of the cyst, rate of complications, wound healing and need for subsequent lines of management.

Results: Patients with satisfactory clinical outcome was observed in most of the total managed cases (72.7\%). There was a statistical significant difference in clinical outcome between the medical management group and the surgical management group as almost medically managed patients $(86.7 \%)$ improved clinically. Improved radiological outcome was observed in $42.9 \%$ of surgically managed patients. Postoperative complications were observed in the majority of surgically managed patients. Most common complication was hydrocephalus in $42.9 \%$ of patients.
\end{abstract}

Conclusion: Management of intracranial arachnoid cysts remained controversial, and most of the patients managed conservatively, but we believe that proper clinical and radiological evaluation of symptomatic arachnoid cysts leads to better outcome.

Keywords: Intracranial arachnoid cyst, conservative versus surgical management.

\section{INTRODUCTION}

Arachnoid cysts can be classified as primary developmental cysts or secondary cysts, Primary cysts arise from the splitting of the arachnoid membranes in utero, resulting in the development of anomalous collections of cerebrospinal fluid (CSF). Secondary cysts are less common, often appearing after trauma, surgery, infection, or intracranial hemorrhage. The prevalence in adults is approximately $1.4 \%$, while the prevalence in children is $2.6 \%$ (Ali et al., 2015).

The most common locations for intracranial arachnoid cysts are the middle fossa (near the temporal lobe), the suprasellar region (near the third ventricle) and the posterior fossa, which 
contains the cerebellum, pons, and medulla oblongata (Stratejileri et al., 2012). The presenting symptoms and signs are closely related to the expansion of arachnoid. Some cysts remain asymptomatic while others may expand and cause symptomatic compression on surrounding structures (Ali et al., 2014).

Progressive growth of arachnoid cysts may cause secondary regional effects such as hypoplasia of the temporal lobe they may manifest with symptoms such as seizures, developmental delay, visual loss, or motor deficits. Patients with arachnoid cysts may also present with hemorrhagic events, especially following head trauma (Al-Holou et al., 2010).

Whether to treat all arachnoid cysts, as well as the method of treatment, has been a subject of controversy in the medical literature. The need for treatment depends mostly upon the location and size of the cyst, as well as whether symptoms are present. Some believe that treatment should be reserved for individuals with symptoms, while others believe that even asymptomatic cysts should be treated to avoid future complications (Shim et al., 2013).

The current study aimed to evaluate the cases of intracranial arachnoid cysts clinically, radio logically, and the possibility of surgery.

\section{PATIENTS AND METHODS}

The study was done prospectively on 22 patients presented with intracranial arachnoid cysts. (15 of them were medically managed and 7 of them were surgically managed) in the Al- Azhar and Alexandria universities neurosurgical departments. The study was performed through the period from March 2019 to February 2020, and the follow up period was 6 months.

\section{-Inclusion criteria:}

Patients with arachnoid cyst either symptomatic or Asymptomatic (accidentally discovered).

\section{-Exclusion criteria:}

History of previous brain surgery, history of CNS infection and medically unfit patients for surgical cases.

All the following were done: Careful history taking, general and careful neurological examination had been conducted among all patients in study according to the following points: Personal data, Complaint, Present history, Past history, Family history, Clinical examination, Investigation (Non contrast CT and or MRI brain had been the radiological standard tools in our study, radiological follow up (CT or MRI) was done after 6 months in conservatively managed patients and during 1st week or as emergency in surgically managed patients).

\section{Plane for the conservatively managed cases:}

The management for conservatively managed cases is a nonspecific and involves only symptomatic treatment for 6 to 12 months (analgesic and antiepilepticis the most common used medication).

\section{Procedures for the surgical cases:}

Surgery was done immediately for arachnoid cysts located along major cerebrospinal fluid (CSF) pathways and are usually of a size which might potentially hamper CSF circulation (suprasellar, tentorial notch, and 
paraventricular cysts), and the cases that presented initially with complicated arachnoid cyst as hydrocephalus and brainstem compression symptoms, and electively after failure of conservative management which is symptomatic treatment, and arachnoid cysts that showed increase in cyst size radio logically during follow up period.

Surgical treatment of arachnoid cyst has taken many forms over years such as Microscopic craniotomy and fenestration into basal cistern, Endoscopic fenestration and Cystoperitoneals hunting. Selection of the surgical modality depends on proper evaluation, surgeon experience, socioeconomic level of the patient and his consent.

All procedures wer performed under general anesthesia. The shortest trajectory through the thinnest part of the cyst wall to the ventricle or the cistern was planned. The surgical field was prepared and draped to allow a switch to microsurgery if needed. A skin incision is made, and a burr hole is placed accordingly. After opening the Dura mater, the outer cyst membrane is coagulated, and the cyst is entered with the endoscopic work sheath. The endoscope is fixed to the endoscope holder, the trocar is removed, and the cyst is inspected with the 0 and the 30 degree angled diagnostic lens scopes.

After switching to the working scope, the cystoventriculostomy or cystocisternostomy is done at the planned safe point between the cyst and the ventricle or the cistern. It is then widened by a Fogarty balloon catheter and scissor. Multiple Ostia are done if possible. In case of hemorrhage an external ventricular drain is left. At the end of the procedure, the opening is inspected with the $0^{\circ}$ diagnostic scope, and the work sheath is withdrawn and closure of the wound is done.

Postoperative care: Vital signs, conscious level will be assessed frequently using Glasgow coma scale, postoperative medications (antibiotics, antiepileptic if required, pain killers), daily dressing and follow up imaging (CT or MRI was performed during the first week, then during the follow up period at 3-6 months).

The following had been assessed in surgical and conservative cases: Clinical improvement of symptoms, radiological reduction in size of the cyst, the rate of complications, wound healing and the need for subsequent lines of management.

\section{Statistical design:}

Sorting and analysis of data were performed by using Statistical Package for the Social Sciences (SPSS) version 21. In this study the qualitative variables were prescribed using number and percent, Chisquare test was used for analysis (Mont Carlo exact test and Fishers exact test were used as alternatives for Chi-square test if there were many small expected values). Numerical variables were expressed as mean \pm standard deviation, Independent samples t- test (for normal distributed data) or Mann-Whitney U-test (for non-normal distributed data) were used for comparison of means values between groups. P value $(\leq 0.05)$ was adopted as the level of significance. 


\section{RESULTS}

The study included 22 managed cases of arachnoid cyst (15 Medically managed and 7 Surgically managed). The mean age of the totally managed cases was $12.1 \pm 9.3$ years, for the medically managed group was $13.8 \pm 9.4$, and for the surgically managed cases was $8.4 \pm 8.3$. There was no statistical significant difference in age between the medical management group and surgical management group. The study include $63.6 \%$ male cases and $36.4 \%$ female cases.

The most common clinical presentation was headache which was observed in 15 patients $(68.2 \%)$, followed by seizures which was observed in 9 patients (40.9\%). This presentation was followed by vomiting and vestibular symptoms which was observed in 6 patients $(27.3 \%)$. There was no statistical significant difference in clinical presentation between the medical management group and surgical management group.

The most common cyst location in the total managed cases was the temporal in 14 patients $(63.6 \%)$.

Patients in the surgically managed group were subdivided to 3 groups according to type of surgery: Group A was treated by cysto-peritoneal shunt and contained 2 cases $(28.6 \%)$, group B was treated by open craniotomy and microscopic fenestration and contained 2 cases (28.6\%), and group C was treated by endoscopic fenestration and contained 3 cases $(42.9 \%)$ (Table 1).

Table (1): Type of surgery done for management of surgical studied patients

\begin{tabular}{|c|c|c|}
\hline \multirow{2}{*}{ Groups } & \multicolumn{2}{|c|}{ Surgical management group (n=7) } \\
\cline { 2 - 3 } Type of surgery & No. & $\%$ \\
\hline V-P shunt & 2 & 28.6 \\
\hline Microscopic marsupialization & 2 & 28.6 \\
\hline Endoscopic fenestration & 3 & 42.9 \\
\hline
\end{tabular}

Patients with satisfactory clinical outcome were observed in most of the total managed cases in $16(72.7 \%)$ patients. There was a statistical significant difference in clinical outcome between the medical management group and the surgical management group as almost medically managed patients $13(86.7 \%)$ were improved clinically (Table 2 ).

Table (2): Clinical outcome among the studied patients

\begin{tabular}{|c|c|c|c|c|}
\hline $\begin{array}{c}\text { Clinical Groups } \\
\text { outcome }\end{array}$ & Total(n=22) & $\begin{array}{c}\text { Medical } \\
\text { management } \\
\text { group (n=15) }\end{array}$ & $\begin{array}{c}\text { Surgical } \\
\text { management } \\
\text { group (n=7) }\end{array}$ & $\begin{array}{c}\text { P- } \\
\text { value }\end{array}$ \\
\cline { 1 - 4 } Improved & $16(72.7 \%)$ & $13(86.7 \%)$ & $3(42.9 \%)$ & \multirow{2}{*}{$\mathbf{0 . 0 5 4}$} \\
\hline Not -improved & $6(27.3 \%)$ & $2(13.3 \%)$ & $4(57.1 \%)$ & \\
\hline
\end{tabular}

Non improved medically managed patients ( 2 patients) refused any surgical intervention and asked to complete their symptomatic treatment and to follow up. 
Patients were categorized into one of three possible radiological outcome groups (improved, no change and worsen). Improved radiological outcome was observed in $3(42.9 \%)$ of surgically managed patients. All medically managed patients $15(100.0 \%)$ did not change radio logically (Table 3).

Table (3): Radiological outcome among the studied patients

\begin{tabular}{|c|c|c|c|c|}
\hline Characteristics & $\operatorname{Total}(n=22)$ & $\begin{array}{c}\text { Medical } \\
\text { management } \\
\text { group }(n=15)\end{array}$ & $\begin{array}{c}\text { Surgical } \\
\text { management } \\
\text { group }(n=7)\end{array}$ & P-value \\
\hline Improved & $3(13.6 \%)$ & $0(0.0 \%)$ & $3(42.9 \%)$ & \multirow{3}{*}{$<0.005$} \\
\hline No change & $17(77.3 \%)$ & $15(100.0 \%)$ & $2(28.6 \%)$ & \\
\hline Worsen & $2(9.1 \%)$ & $0(0.0 \%)$ & $2(28.6 \%)$ & \\
\hline
\end{tabular}

Most surgically managed cases was complicated $(57.2 \%)$ and $(42.8 \%)$ showed no complications, that most common complication was hydrocephalus in
$3(42.9 \%)$ patients, followed by bleeding and subdural collection in $2(28.6 \%)$ patients for each one (Figure 1).

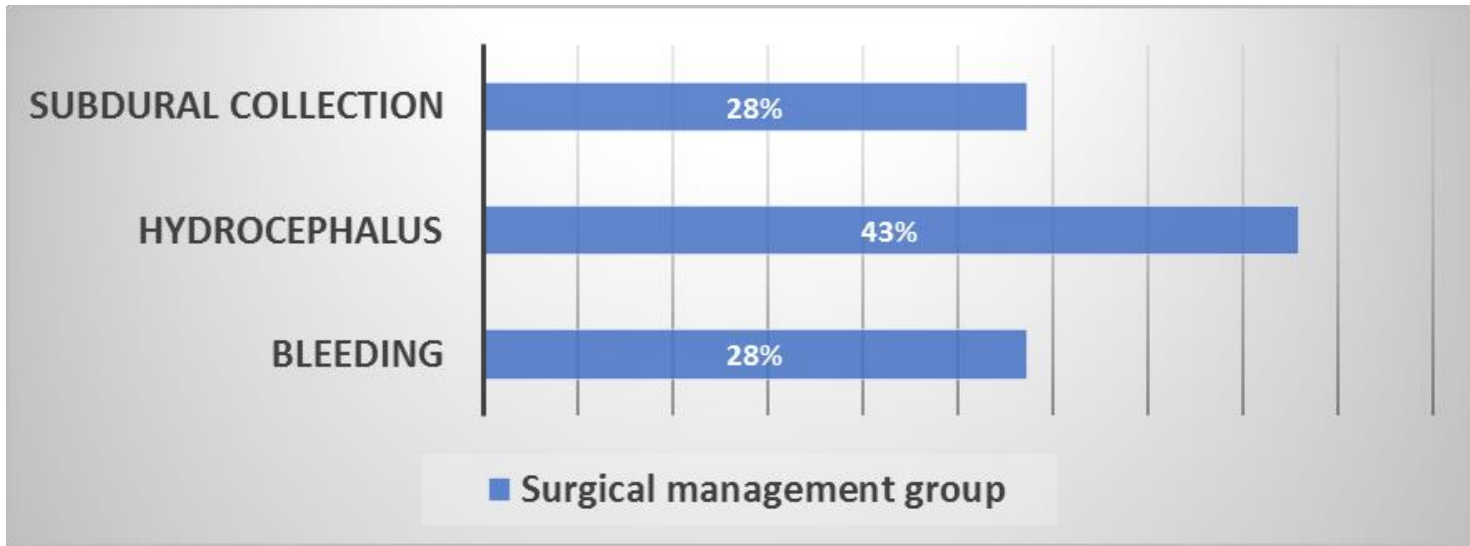

Figure (1): Type and frequency of complications among the complicated Surgical management group

Four patients $(66.6 \%)$ did not need another surgery, while only 2 patients $(33.3 \%)$ need another surgery. Among the patients needed another operation, one

\section{DISCUSSION}

Surgical indications and modalities in treatment of intracranial arachnoid cysts still remain controversial due to limited understanding of the pathophysiologic mechanisms and natural history of this pathology (Holst etal., 2012). patient $(16.6 \%)$ was treated by V-P shunt and another one patient $(16.6 \%)$ was treated by external ventricular drain (EVD).

In our study, the mean age of the total participants was 12.1 years, the mean age of the conservatively managed patients was 13.8 years and the mean age of the surgically managed patients was 8.4 years. This was slightly different from another study in which the mean age was 4.3 years (Lee etal., 2012). 
Regarding clinical presentation in our study, there was not statistical significant difference in clinical presentation between the conservative management group and surgical management group. The most common clinical presentation was headache which was observed in 15 patients $(68.2 \%)$ of the study patients and this was coinciding with the study done by Gangemi et al. in which (56\%) patients was complaining of headache (Gangemi etal., 2011), and another study in which headache was the most common symptom in (32\%) patients (Sharma etal., 2016).

In our study, seizures were observed in 9 patients (40.9\%), followed by vomiting and vestibular symptoms in 6 patients $(27.3 \%)$. This was slightly different from the study done by Gangemi et al. (2011) in which $(18 \%)$ of patients had seizures and another study in which only (14\%) had seizures (Helland etal., 2010).

As regarding the location of the cyst, the most common site was temporal location as was observed in $59.1 \%$ of total patients, (in $53.3 \%$ of conservative management group, and in $57.1 \%$ of surgical management group). This was coinciding with another study as the temporal cyst represented $50.3 \%$ of their studied group (Stratejileri etal., 2012), and another study in which arachnoid cysts have a strong predilection for the temporal fossa (Helland etal., 2010).

In our study, surgical management patients were subdivided to 3 groups according to type of surgery: $28.6 \%$ of patients were treated by cysto-peritoneal shunt, $28.6 \%$ of patients were treated by microscopic fenestration, and $42.9 \%$ of patients were treated by endoscopic fenestration. This was slightly different with the study of Stratejileri etal. (2012) who reported that $33 \%$ were treated by microscopic fenestration, only $20 \%$ were treated by endoscopic fenestration, and $47 \%$ were treated by cystoperitoneal shunting.

In our study, improved clinical outcome was observed in almost medically managed patients $(86.7 \%)$ compared to only $42.9 \%$ of patients of the surgical management group. This was coinciding with the study done by (Hellandet al., 2010), as had been found that symptoms had disappeared completely in $47 \%$ of patients. On another side, another study reported that a clinical improvement was found in all symptomatic children (Di Rocco etal., 2010), and in another study in which about $93 \%$ of patient treated with cystoperitoneal shunt showed good clinical outcome (Gangemi etal., 2011).

In our study, patients were categorized into one of three possible radiological outcome groups (improved, no change and worsen). All medically managed patients $(100.0 \%)$ were not changed radio logically. Improved radiological outcome was observed in $42.9 \%$ of surgically managed patients. On another hand, the results of another study (Wang etal., 2015) showed cyst reduction was achieved in $77.8 \%$ of patients at the last follow-up after cystoperitoneal shunting. Another study showed improvement or resolution of symptoms was seen in $88 \%$ of patients treated endoscopic ally, $88 \%$ of patients treated micro surgically, and $100 \%$ of patients treated by shunting (Hall etal., 2019). 
In our study, postoperative complications were observed in the majority of surgically managed patients (57.2\%). Most common complication was hydrocephalus in $42.9 \%$ of patients, followed by bleeding and subdural collection in $28.6 \%$ of patients in each one. These findings differed from the results of another study as endoscopic treatment of arachnoid cysts resulted in subdural hematomas in $5 \%$ of cases (Johnson et al., 2011). Another study showed that $4 \%$ of patients presented with postoperative hemorrhage in cyst (Sharma etal., 2016).

This difference may be due to: the use of more advanced instruments (endoscopes and microscopes), less surgeon experience, limited sample size, and short period of our study.

In our study, only $28.6 \%$ needed another surgery. This was slightly different from the results of another study as $38.8 \%$ required a second intervention to resolve the clinical condition (Yadav etal., 2013).

\section{CONCLUSION}

Proper clinical and radiological evaluation of symptomatic arachnoid cyst leads to better outcome. In patients with symptomatic arachnoid cystthe need for surgery was variable according to: cyst location, mass effect, impact on CSF flow dynamics, e.g. hydrocephalus, focal neurological deficits, headaches, seizures, and developmental/cognitive deficits.

Selection of the surgical modality depends on proper evaluation, cyst location, size, associated complications, surgeon experience and patient consent. There was no clear advantage of neuroendoscopic fenestration of sylvian arachnoid cysts compared with minicraniotomic approaches both in terms of clinical benefits and in relation to complications rates. Long term follows up of the patients will lead to more experience.

\section{REFERENCES}

1. Ali, Z. S., Lang, S. S., Bakar, D., Storm, P. B. and Stein, S. C. (2014): Pediatric intracranial arachnoid cysts: comparative effectiveness of surgical treatment options. Child's Nervous System, 30(3): 461-469.

2. Ali, M., Bennardo, M., Almenawer, S. A., Zagzoog, N., Smith, A. A., Dao, D. and Singh, S. K. (2015): Exploring predictors of surgery and comparing operative treatment approaches for pediatric intracranial arachnoid cysts: a case series of 83 patients. Journal of Neurosurgery: Pediatrics, 16(3): 275-282.

3. Al-Holou, W. N., Yew, A. Y., Boomsaad, Z. E., Garton, H. J., Muraszko, K. M. and Maher, C. O. (2010): Prevalence and natural history of arachnoid cysts in children. Journal of Neurosurgery: Pediatrics, 5(6): 578-585.

4. Di Rocco, F., James, S. R., Roujeau, T., Puget, S., Sainte-Rose, C. and Zerah, M. (2010): Limits of endoscopic treatment of sylvian arachnoid cysts in children. Child's Nervous System, 26(2): 155.

5. Gangemi, M., Seneca, V., Colella, G., Cioffi, V., Imperato, A. and Maiuri, F. (2011): Endoscopy versus microsurgical cyst excision and shunting for treating intracranial arachnoid cysts. Journal of Neurosurgery: Pediatrics, 8(2): 158-164.

6. Hall, S., Smedley, A., Rae, S., Mathad, N., Waters, R., Chakraborty, A. and Tsitouras, V. (2019): Clinical and radiological outcomes following surgical treatment for intra-cranial arachnoid cysts. Clinical Neurology and Neurosurgery, 177: 42-46.

7. Holst, A. V., Danielsen, P. L. and Juhler, M. (2012): Treatment options for intracranial arachnoid cysts: a retrospective study of 69 
patients. In Intracranial Pressure and Brain Monitoring XIV. Springer, Vienna: 267-270.

8. Helland, C. A., Lund-Johansen, M. and Wester, K. (2010): Location, sidedness, and sex distribution of intracranial arachnoid cysts in a population-based sample. Journal of Neurosurgery, 113(5): 934-939.

9. Johnson, R. D., Chapman, S. and Bojanic, S. (2011): Endoscopic fenestration of middle cranial fossa arachnoid cysts: Does size matter? Journal of Clinical Neuroscience, 18(5): 607612.

10. Lee, J. Y., Kim, J. W., Phi, J. H., Kim, S. K., Cho, B. K. and Wang, K. C. (2012): Enlarging arachnoid cyst: a false alarm for infants. Child's Nervous System, 28(8): 12031211.

11.Sharma, M., Mittal, R. S., Bansal, R. and Sharma, A. (2016): Intracranial arachnoid cyst: An institutional experience. Romanian Neurosurgery: 136-142.
12.Shim, K. W., Lee, Y. H., Park, E. K., Park, Y. S., Choi, J. U. and Kim, D. S. (2013): Treatment option for arachnoid cysts. Child's Nervous System, 25(11): 1459.

13. Stratejileri, İ. A. K. C. Y., Merkezin, B. and Tecrübesi, O. (2012): Surgical management strategies of intracranial arachnoid cysts: a single institution experience of 75 cases. Turkish Neurosurgery, 22(5): 591-598.

14. Wang, Y., Wang, F., Yu, M., \& Wang, W. (2015): Clinical and radiological outcomes of surgical treatment for symptomatic arachnoid cysts in adults. Journal of Clinical Neuroscience, 22(9), 1456-1461.

15. Yadav, Y. R., Parihar, V. and Bhatele, P. (2013): Endoscopic treatment of arachnoid cyst. In Proceedings of All India Seminar on Biomedical Engineering 2012 (AISOBE 2012), pp. 29-35. ph.Springer, India. 


\section{علاج الأكياس المخية الخلقية (تحفظى مقابل جر احى)} على مجدى الثربينى، إسلام محمد الأجهوري، أسامه محمد الغتام قسم جراحة المخ والأعصاب، كلية الطب، جامعة الأزهر، القاهره

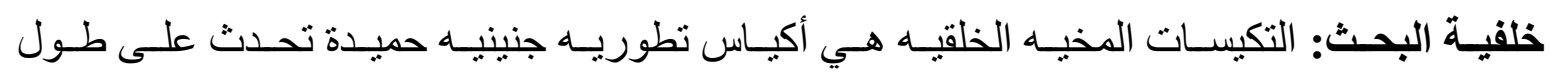

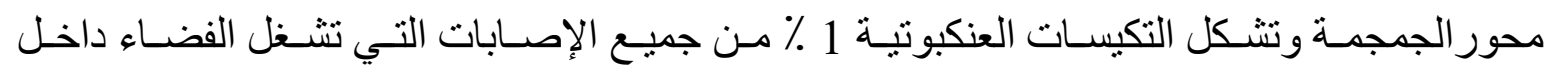

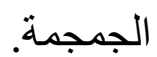

الهذف من البحث: تقييم حالات الأكياس المخيه العنكبوتيه داخل الجمجمة سريريًا وإثـعاعيًا، وبيـان

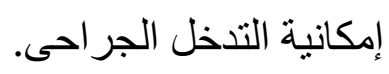

المرضى و طرق البحث: أجريت الدراسـة على 22 مريضًا يعانون من تكيسات عنكبوتيهـ داخل

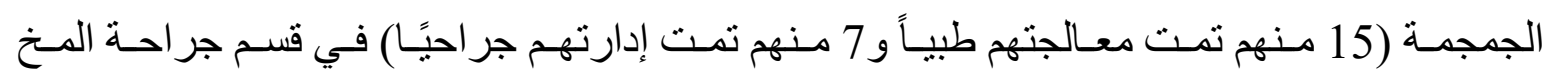

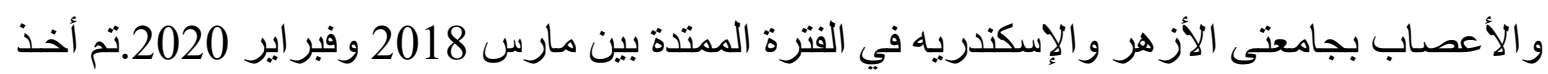

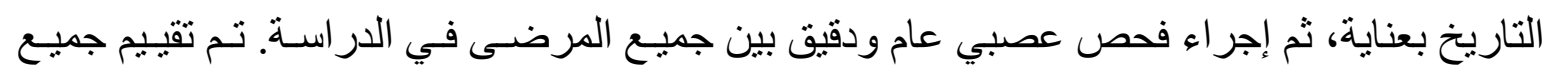

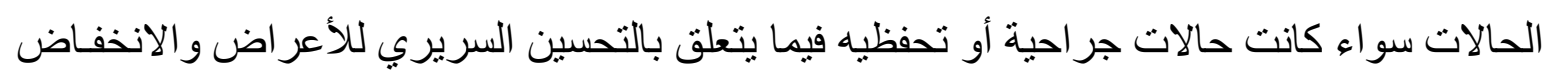

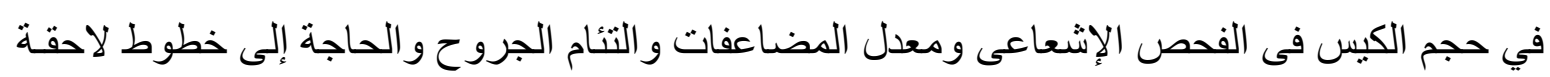
لأستكمال العلاج و علاج المضاعفات.

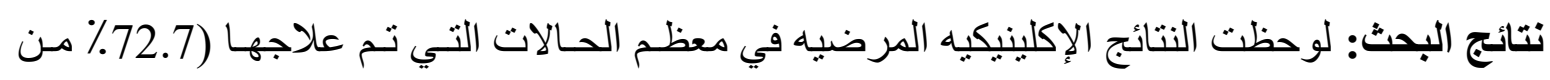

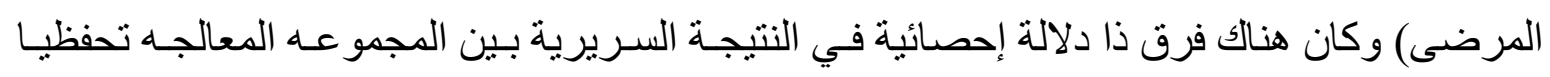

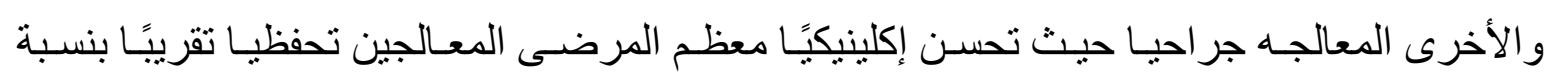

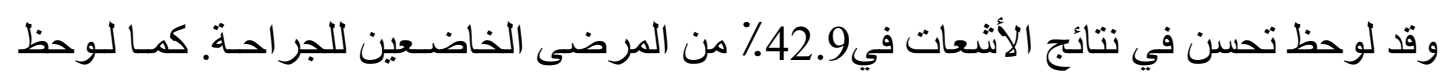

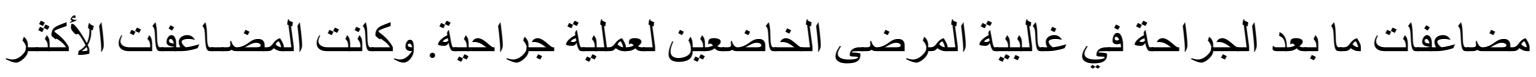
شيو عاً هي استسقاء الر أسلاى 42.9٪ من غن المرضى.

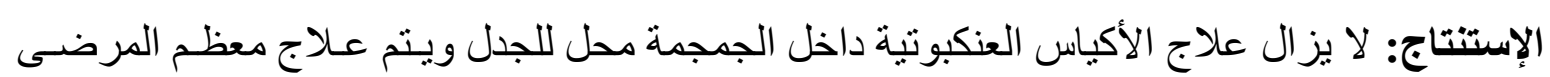

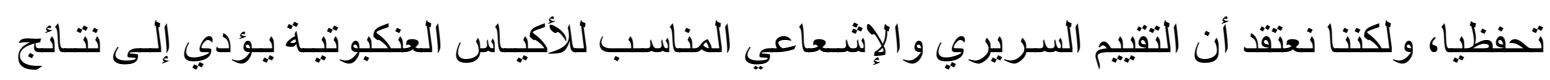

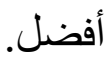

